\title{
Survey of Clinical Practice for Irritable Bowel Syndrome in East Asian Countries
}

\author{
Shin Fukudo ${ }^{f}$ Ki-Baik Hahm ${ }^{\text {a }}$ Qi Zhu ${ }^{b}$ Jose D. Sollano ${ }^{c}$ Abdul A. Rani ${ }^{d}$ \\ Ari F. Syam ${ }^{d}$ Udom Kachintorn $^{\mathrm{e}}$ Hidekazu Suzukig Takeshi Kamiya ${ }^{\mathrm{i}}$ Takashi Joh $^{\mathrm{i}}$

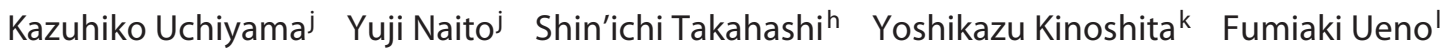 \\ Hirokazu Yamagamim, ${ }^{n}$ Francis K.L. Chan ${ }^{\circ}$ Kwong M. Fock ${ }^{p}$ Tetsuo Arakawam, $n$ \\ The International Gastrointestinal Consensus Symposium Study Group

\begin{abstract}
a Digestive Disease Center, CHA University School of Medicine and CHA University Bundang Medical Center, Seongnam, Republic of Korea; ${ }^{b}$ Gleneagles Medical and Surgical Center, Parkway Health China, and Rui Jin Hospital, Shanghai Jiao Tong University School of Medicine, Shanghai, PR China; ' ${ }^{\mathrm{D}}$ Department of Medicine, University of Santo Tomas, Manila, Republic of the Philippines; ${ }^{\mathrm{d}}$ Department of Internal Medicine, Faculty of Medicine, Cipto Mangunkusumo Hospital and Indonesian University School of Medicine, University of Indonesia, Jakarta, Indonesia; ' Division of Gastroenterology, Department of Internal Medicine, Faculty of Medicine, Siriraj Hospital, Mahidol University, Bangkok, Thailand; fDepartment of Behavioral Medicine, Tohoku University Graduate School of Medicine, Sendai, ${ }^{9}$ Department of Internal Medicine, Keio University School of Medicine, and hepartment of Gastroenterology, Kyorin University School of Medicine, Tokyo, 'Department of Gastroenterology and Metabolism, Nagoya City University Graduate School of Medical Sciences, Nagoya, jDepartment of Molecular Gastroenterology

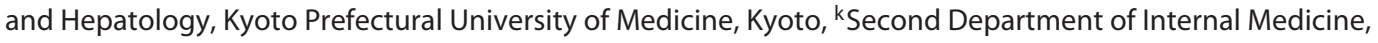
Shimane University School of Medicine, Izumo, 'Department of Medicine, Ofuna Chuo Hospital, Kamakura, and ${ }^{m}$ Division of Gastroenterology and Hepatology and ${ }^{n}$ Department of Gastroenterology, Osaka City University Graduate School of Medicine, Osaka, Japan; ${ }^{\circ}$ Faculty of Medicine, The Chinese University of Hong Kong,

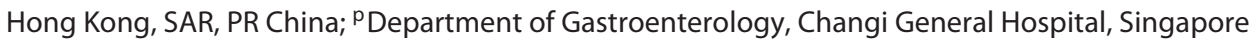

\section{Key Words}

Irritable bowel syndrome · Functional gastrointestinal disorders · Rome III criteria · East Asian countries

\begin{abstract}
Aim: Sociocultural factors are important because their different effects on the features of irritable bowel syndrome (IBS) between countries will provide clues towards solving this problem. The aims of this study were to depict the clinical realities of IBS in East Asian countries and test the hypothesis that the diagnosis and treatment of IBS differ between countries. Subjects and Methods: Study participants were 251 physicians involved in the clinical practice of IBS at major institutions in Japan, South Korea, China, the Philippines, Indonesia and Singapore. The questionnaire contained 45 questions focused on the clinical practice of IBS. Results: Subjects
\end{abstract}

(c) 2015 S. Karger AG, Basel

0012-2823/15/0911-0099\$39.50/0 in Japan, South Korea, China, Indonesia, the Philippines and Singapore accounted for 55.4, 17.9, 8.8, 8.0, 6.4 and $3.6 \%$ of the study cohort, respectively. Amongst East Asian physicians, the most important symptom was considered to be abdominal pain by $33.4 \%$, whilst $24.3 \%$ regarded alternating diarrhea and constipation to be the most important symptoms. Total colonoscopy and histopathology use showed no difference among countries. Prescriptions given for mild ( $p<0.0001)$, moderate $(p<0.0001)$, severe $(p<0.0001)$, intractable $(p=$ $0.002)$, diarrheal $(p<0.0001)$ and constipating $(p<0.0001)$ patients with IBS significantly differed between the countries. Except for several minor points, IBS specialists showed no significant difference in their diagnosis and treatment of IBS when compared to nonspecialists. Conclusion: This survey provided data on the clinical treatment of IBS among East Asian countries. The results supported the hypothesis that the diagnosis and treatment of IBS differs between countries.

(c) 2015 S. Karger AG, Basel

Prof. Shin Fukudo, MD, PhD

Department of Behavioral Medicine

Tohoku University Graduate School of Medicine

2-1 Seiryo-machi, Aoba-ku, Sendai 980-8575 (Japan)

E-Mail sfukudo@med.tohoku.ac.jp 


\section{Introduction}

Irritable bowel syndrome (IBS) is a prototype of and the most representative functional gastrointestinal disorder (FGID) [1]. According to the Rome III criteria [2], IBS is defined as recurrent abdominal pain or discomfort for at least 3 days per month over the preceding 3 months, associated with 2 or more of the following: improvement with defecation, onset associated with a change in stool frequency and/or onset associated with a change in the form (appearance) of stool. These criteria should be fulfilled for the previous 3 months with symptom onset at least 6 months prior to diagnosis. IBS is very common, with a prevalence of $10-20 \%$ in the general population [3]. Health-related quality of life is greatly disturbed in patients with IBS [4]. IBS is associated with substantial costs to patients, healthcare systems and society [5]. Therefore, appropriate diagnosis and effective treatment for IBS provide considerable benefit not only for the patients themselves, but also for society in general.

Multiple factors affect the features of IBS [1]. These include psychosocial stress, infection, gut microbiota, genetics and learning, as well as gender, age, society, culture and patient perspective [6]. Among them, the biological factors are essential because they provide a universal principle for the management of IBS. Sociocultural factors are also important because the differing effects of such factors on the features of IBS between countries will provide great hints towards solving the IBS problem. Cross-cultural comparative research will make a significant contribution to IBS research through epidemiology, genetics, psychosocial modulators, symptom reporting and interpretation, extraintestinal comorbidities, diagnosis and treatment, determinants of disease severity, healthcare utilization and health-related quality of life all issues that may be affected by geographical region, culture, ethnicity and race [7].

East Asian countries have some features specific to their geographical region. They are located on the east coast of the Eurasian continent with moderate-to-hot temperatures and humidity. They have some similarities and differences in culture, habitat and race. Dietary patterns and gut microbiota are different between Asians and Europeans/Americans [8]. Comparative gut metagenome analyses show that porphyranases and agarases are frequent in the Japanese population, and that they are absent in metagenome data from North American individuals. To date, several features of IBS in Asia have been studied [9] and a survey was conducted on FGIDs, including
IBS and functional dyspepsia (FD), among 43 physicians and researchers in the Asia-Pacific region [10]. However, there has not been a survey comparing the clinical practice of IBS among East Asian countries involving a considerable number of physicians. The aims of this study were as follows: (1) to depict the clinical realities of IBS in East Asian countries; (2) to test the hypothesis that the diagnosis and treatment of IBS differs between countries, and (3) to test the hypothesis that the diagnosis and treatment of IBS differs between IBS specialists and nonspecialists.

\section{Subjects and Methods}

The study participants were 251 physicians involved in the clinical practice of IBS at major institutions in Japan, South Korea (Korea), China, the Philippines, Indonesia and Singapore. All participants work in an urban environment. This is the 7th questionnaire-based survey conducted by the International Gastrointestinal Consensus Symposium (IGICS). The IGICS is a gastroenterological study group in the countries of East Asia, including Japan, Korea, China, the Philippines, Indonesia, Singapore and Thailand. The IGICS holds a yearly gathering at the annual meeting of the Japanese Gastroenterological Association (JGA). The 7th IGICS was held in Fukushima, Japan, in February 2014, under the presidency of the first author (S.F.). The survey for the clinical practice of IBS was commenced following the meeting.

Representative IGICS committee members provided a questionnaire to selected physicians in each country, starting in February 2014. Responses were collected by electronic mail until May 2014. The questionnaire contained 45 questions focused on the following items: country, discipline, specialty, motivation of IBS care, number of patients with IBS per month, number of patients with FD per month, number of patients with microscopic colitis, the most important symptoms in IBS, laboratory examination, imaging examination, evaluation of the Rome criteria, major differential diagnosis, treatment for mild, moderate, severe and intractable patients with IBS, treatment for IBS with diarrhea (IBS-D) or IBS with constipation (IBS-C), and use of kampo (Chinese herbal) medicine. The details of the questionnaire are provided in the Appendix.

The data were statistically analyzed with Statistical Package for Social Science (SPSS) version 22.0 (IBM Japan, Tokyo, Japan), and summarized with actual number, rate or mean \pm standard error (SE). Six groups were compared with $\chi^{2}$ analysis or Kruskal-Wallis test. Two groups were compared with $\chi^{2}$ analysis or Mann-Whitney $\mathrm{U}$ test. A p value $<0.05$ was regarded as significant.

\section{Results}

\section{Overall IBS Practice in East Asian Countries}

A total of 251 questionnaires were obtained from 251 physicians. Among them, Japan, Korea, China, Indonesia, the Philippines and Singapore accounted for 55.4, 
$17.9,8.8,8.0,6.4$ and $3.6 \%$, respectively (table 1 ). The majority $(87.6 \%)$ of respondents were gastroenterologists, followed by general internists (9.2\%) and epidemiologists (2.0\%). IBS specialists consisted of $23.5 \%$ of the subjects, and the remaining $76.5 \%$ were nonspecialists. Although the majority were not IBS specialists, $62.2 \%$ of them expressed motivation to see IBS patients.

The average number of IBS patients per institution was $49.9 \pm 11.2$ per month. The number of patients with FD at each institution $(80.1 \pm 16.4$ per month) was significantly more than that of IBS patients $(\mathrm{p}<0.0001)$. The number of patients with microscopic colitis at each institution was $18.3 \pm 5.9$ per year. The majority $(33.4 \%)$ of East Asian physicians considered abdominal pain to be the most important symptom. This was followed by $24.3 \%$ who considered alternating diarrhea and constipation as the most important symptoms, whilst abdominal discomfort, diarrhea, constipation, abdominal bloating, gas and urgency were viewed as the most important by 22.7 , $14.3,2.0,1.6,0.4$ and $0.4 \%$, respectively.

A laboratory examination for the diagnosis of IBS, including always performing a complete blood count (CBC), C-reactive protein (CRP), erythrocyte sedimentation rate (ESR) and stool calprotectin, was supported by less than $50 \%$ of physicians (table 2). A microbial stool test and Clostridium difficile detection were also performed by less than $50 \%$ of physicians. In contrast, total colonoscopy was always performed by $57.8 \%$ of physicians. Other imaging examinations for the diagnosis of IBS, including always performing flexible sigmoidoscopy, rigid proctoscopy, barium enema, capsule endoscopy, computed tomography (CT)/magnetic resonance imaging (MRI) colonography, upper gastrointestinal endoscopy and ultrasonography, were supported by less than $50 \%$ of physicians. Regarding diagnostic criteria, 86.5 and $66.5 \%$ of physicians supported the IBS definition and subtyping of IBS according to the Rome III criteria, and the majority (87.3\%) will use the forthcoming Rome IV criteria. Nearly half (45.8\%) of the physicians regard inflammatory bowel disease (IBD) to be the major consideration when making a differential diagnosis from IBS. The following diseases were nominated by other physicians: microscopic colitis (8.8\%), infectious enterocolitis (8.8\%), colorectal cancer (7.6\%), other FGIDs (5.2\%) and other diseases or no answer given (23.9\%). Approximately three quarters $(73.7 \%)$ of physicians stated that the most important protocol with which to diagnose IBS was the Rome III criteria, followed by colonoscopy (24.3\%), histopathology (1.6\%) and blood chemical examinations $(0.4 \%)$.

Survey of Clinical Practice for IBS in East Asian Countries
Table 1. Physicians $(n=251)$ treating IBS patients in East Asia

\begin{tabular}{lc}
\hline Country & \\
Japan & $139(55.4)$ \\
Korea & $45(17.9)$ \\
China & $22(8.8)$ \\
Indonesia & $20(8.0)$ \\
Philippines & $16(6.4)$ \\
Singapore & $9(3.6)$ \\
Discipline & \\
Gastroenterology & $220(87.6)$ \\
General internist & $23(9.2)$ \\
Epidemiologist & $5(2.0)$ \\
N/A & $3(1.2)$ \\
Specialty & \\
IBS & $59(23.5)$ \\
Not IBS & $192(76.5)$ \\
Level of motivation of IBS care & \\
More motivated & $156(62.2)$ \\
Less motivated & $90(35.9)$ \\
N/A & $5(2.0)$ \\
IBS patients/month (238 physicians) & $49.9 \pm 11.2$ \\
FD patients/month (237 physicians) & $80.1 \pm 16.4$ \\
Microscopic colitis patients/year & \\
(251 physicians) & $18.3 \pm 5.9$
\end{tabular}

Data are presented as $n$ with percentage in parentheses or mean $\pm \mathrm{SE} . \mathrm{N} / \mathrm{A}=\mathrm{No}$ answer.

Considering the treatment of IBS, for patients with mild conditions, probiotics was the most popular prescription (table 3). For moderate IBS patients, selective serotonin reuptake inhibitor (SSRI) and tricyclic antidepressant (TCA) are two major prescriptions. For severe IBS patients, antipsychotics and cognitive behavior therapy (CBT) are two major strategies. At present there is no common method for the treatment intractable IBS patients in East Asia, but $31.1 \%$ of physicians use Chinese (Japanese) herbal medicine (kampo). Approximately one third (34.7\%) of physicians supported the administration of 3-HT3 antagonist to IBS-D patients, and 27.5 and $21.1 \%$ supported the use of loperamide and anticholinergics, respectively. For IBS-C patients, 34.7, 22.3 and 22.3\% of physicians used 5-HT4 agonist, bisacodyl-picosulfate and lactulose, respectively.

\section{Difference in IBS Practice among Asian Countries}

The number of patients with IBS in Japan (12.2 \pm 1.3$)$, Indonesia (17.2 \pm 5.4$)$, the Philippines (25.7 \pm 9.3$)$, Singapore $(61.9 \pm 40.0)$, Korea $(116.1 \pm 34.2)$ and China $(179.4 \pm 91.6)$ were significantly different $(\mathrm{p}<0.0001$; fig. 1a). The number of patients with FD in the Philippines $(21.7 \pm 7.7)$, Japan $(23.4 \pm 3.8)$, Indonesia (36.7 \pm 
Table 2. Diagnosis of IBS patients in East Asia

\begin{tabular}{|c|c|c|c|c|}
\hline \multicolumn{5}{|l|}{ Laboratory examination } \\
\hline $\mathrm{CBC}$ & Always & $106(42.2)$ & Other & $145(57.8)$ \\
\hline CRP & Always & $87(34.7)$ & Other & $164(65.3)$ \\
\hline ESR & Always & $28(11.2)$ & Other & $223(88.8)$ \\
\hline Stool calprotectin & Always & $6(2.4)$ & Other & $245(97.6)$ \\
\hline \multicolumn{5}{|l|}{ Imaging examination } \\
\hline Total colonoscopy & Always & $145(57.8)$ & Other & $106(42.2)$ \\
\hline Flexible sigmoidoscopy & Always & $2(0.8)$ & Other & $249(99.2)$ \\
\hline Rigid proctoscopy & Always & $2(0.8)$ & Other & $249(99.2)$ \\
\hline Barium enema & Yes & $14(5.6)$ & No & $237(94.4)$ \\
\hline Capsule endoscopy & Yes & $13(5.2)$ & No/not available & $238(94.8)$ \\
\hline Rome III & Yes & $217(86.5)$ & $\mathrm{No} / \mathrm{N} / \mathrm{A}$ & $34(13.5)$ \\
\hline Subtyping with Rome III & Yes & $167(66.5)$ & No/N/A & $84(33.5)$ \\
\hline Willing to use Rome IV & Yes & $219(87.3)$ & $\mathrm{No} / \mathrm{N} / \mathrm{A}$ & $32(12.7)$ \\
\hline \multicolumn{5}{|l|}{ Major differential diagnosis } \\
\hline IBD & & $115(45.8)$ & & \\
\hline Microscopic colitis & & $22(8.8)$ & & \\
\hline Infectious enterocolitis & & $22(8.8)$ & & \\
\hline Colorectal cancer & & $19(7.6)$ & & \\
\hline Other FGIDs & & $13(5.2)$ & & \\
\hline Other or N/A & & $60(23.9)$ & & \\
\hline
\end{tabular}

10.7), Korea (149.9 \pm 34.3$)$, Singapore $(240.0 \pm 210.2)$ and China (295.6 \pm 137.1$)$ were also significantly different ( $p<0.0001$; fig. 1b). The number of patients with microscopic colitis in Japan $(4.0 \pm 0.8)$, Singapore $(5.7 \pm 2.1)$, Korea $(7.8 \pm 1.1)$, the Philippines $(9.3 \pm 6.3)$, Indonesia $(18.3 \pm 5.4)$ and China (141.4 \pm 51.0$)$ were significantly different between the countries $(\mathrm{p}<0.0001)$. The percentage of IBS specialists amongst the respondents significantly differed between Indonesia (10.0\%), Japan (15.1\%), Singapore $(22.2 \%)$, China $(31.8 \%)$, the Philippines $(37.5 \%)$ and Korea $(46.7 \%$; $<<0.0001)$.

The most important symptoms in the diagnosis of IBS significantly differed among countries ( $\mathrm{p}<0.0001$; fig. 2a). Physicians in Korea, China, Indonesia, the Philippines and Singapore regarded abdominal pain and abdominal discomfort to be the most important symptoms. In contrast, a considerable rate (38.1\%) of physicians in Japan considered alternating diarrhea and constipation to be the most important symptoms in IBS, as well as abdominal pain and abdominal discomfort. There was no difference in use of the Rome III criteria to diagnose IBS among the countries. However, subtyping IBS using the Rome III criteria significantly differed between Japan (54.7\%), Korea (84.4\%), China (72.7\%), Indonesia (75.0\%), the Philippines (87.5\%) and Singapore (88.9\%; $\mathrm{p}=0.008$; fig. $2 \mathrm{~b}$ ). There was no difference in willingness to use the forthcoming Rome IV criteria to diagnose IBS between the countries.

Laboratory examination for the diagnosis of IBS, including CBC $(p=0.015), \operatorname{ESR}(p=0.002), C R P(p<0.0001)$ and stool calprotectin $(\mathrm{p}<0.0001)$, significantly differed between the countries. Japanese physicians favored CBC and CRP and rarely examined stool calprotectin. Imaging examination for the diagnosis of IBS, including flexible sigmoidoscopy $(\mathrm{p}<0.0001)$, rigid proctoscopy $(\mathrm{p}=0.005)$, barium enema $(p=0.045)$ and upper gastrointestinal endoscopy $(\mathrm{p}=0.003)$, significantly differed between the countries. Performing capsule endoscopy or CT/MRI colonography revealed no meaningful difference between the countries. Japanese physicians favored upper gastrointestinal endoscopy and rarely performed flexible sig- 
moidoscopy, rigid proctoscopy and barium enema. Total colonoscopy and abdominal ultrasonography application showed no difference between the countries; however, the role of histopathology significantly differed $(\mathrm{p}<0.0001)$. The major diseases to be differentially diagnosed significantly differed among the countries $(\mathrm{p}=0.003)$. Japanese physicians aimed to distinguish IBD from IBS, and Korean and Chinese physicians made an effort to discriminate microscopic colitis from IBS. There were no differences in microbial stool testing and $C$. difficile detection.

The prescriptions given for mild ( $\mathrm{p}<0.0001)$, moderate $(\mathrm{p}<0.0001)$, severe $(\mathrm{p}<0.0001)$ and intractable $(\mathrm{p}=$ 0.002 ) patients with IBS significantly differed between the countries. Probiotics was the most popular prescription for mild IBS patients in Japan, China and Indonesia, but not in Korea, the Philippines and Singapore (fig. 3a). Compared to their contemporaries in the other countries, Japanese physicians prescribed fewer SSRIs and TCAs for moderate IBS patients (fig. 3b). Japanese, Korean and Chinese physicians prescribed more antipsychotics for severe IBS patients than their colleagues in Indonesia, the Philippines and Singapore (fig. 3c). For intractable IBS patients, physicians in Korea (20.0\%), Indonesia (15.0\%), China (13.6\%) and Singapore (11.1\%) used opioid. However, opioid use was not so frequent in clinical practice in the Philippines (6.3\%) and Japan (3.6\%). The prescription for IBS-D $(\mathrm{p}<0.0001)$ and IBS-C $(\mathrm{p}<0.0001)$ patients significantly differed among countries. Physicians in Japan, Korea, China and the Philippines used more 5-HT3 antagonists compared with those in Indonesia or Singapore (fig. 3d). Physicians in Japan, China and Singapore used lubiprostone, but those in Korea, Indonesia and the Philippines did not (fig. 3d). Use of kampo significantly differed between the countries ( $\mathrm{p}<0.0001)$. Japanese $(47.5 \%)$ and Chinese (45.5\%) physicians prescribed kampo for IBS, but those in the other countries did not.

\section{Difference in IBS Practice between IBS Specialists and Nonspecialists}

IBS specialists treated significantly more patients with IBS $(\mathrm{p}<0.0001), \mathrm{FD}(\mathrm{p}<0.0001)$ and microscopic colitis $(\mathrm{p}<0.0001)$ than nonspecialists. IBS specialists $(86.4 \%)$ significantly expressed more positive will than nonspecialists $(54.7 \%$; $<0.0001)$. The two groups showed no significant difference in the diagnosis and treatment of IBS, except for the following minor points: flexible sigmoidoscopy $(\mathrm{p}=0.008)$ and rigid proctoscopy $(\mathrm{p}=0.026)$ were performed less by the specialists, and $C$. difficile detection ( $\mathrm{p}=0.008$ ) was performed more by the specialists than nonspecialists.

Survey of Clinical Practice for IBS in East Asian Countries
Table 3. Treatment of IBS patients in East Asia

\begin{tabular}{|c|c|}
\hline Condition and treatment choice & Physicians $(\mathrm{n}=251)$ \\
\hline \multicolumn{2}{|l|}{ Mild IBS } \\
\hline Probiotics & $137(54.6)$ \\
\hline Trimebutine & $39(15.5)$ \\
\hline Bulking polymer & $36(14.3)$ \\
\hline Anticholinergics & $28(11.2)$ \\
\hline Other or N/A & $11(4.4)$ \\
\hline \multicolumn{2}{|l|}{ Moderate IBS } \\
\hline SSRI & $94(37.5)$ \\
\hline TCA & $70(27.9)$ \\
\hline SNRI & $5(2.0)$ \\
\hline NaSSA & $3(1.2)$ \\
\hline Other or N/A & $78(31.4)$ \\
\hline \multicolumn{2}{|l|}{ Severe IBS } \\
\hline Antipsychotics & $92(36.7)$ \\
\hline $\mathrm{CBT}$ & $61(24.3)$ \\
\hline Brief psychotherapy & $26(10.4)$ \\
\hline Hypnotherapy & $3(1.2)$ \\
\hline Other or N/A & $69(27.5)$ \\
\hline \multicolumn{2}{|l|}{ Intractable IBS } \\
\hline 5-ASA & $39(15.5)$ \\
\hline NSAIDs & $33(13.1)$ \\
\hline Opioid & $22(8.8)$ \\
\hline Pregabalin & $21(8.4)$ \\
\hline Steroid & $8(3.2)$ \\
\hline Other or N/A & $128(51.0)$ \\
\hline \multicolumn{2}{|l|}{$I B S-D$} \\
\hline 5-HT3 antagonist & $87(34.7)$ \\
\hline Loperamide & $69(27.5)$ \\
\hline Anticholinergics & $53(21.1)$ \\
\hline Cholestyramine & $3(1.2)$ \\
\hline Others or N/A & $39(15.5)$ \\
\hline \multicolumn{2}{|l|}{$I B S-C$} \\
\hline 5-HT4 agonist & $68(27.1)$ \\
\hline Bisacodyl-picosulfate & $56(22.3)$ \\
\hline Lactulose & $56(22.3)$ \\
\hline Lubiprostone & $23(9.2)$ \\
\hline Polyethylene glycol & $15(6.0)$ \\
\hline Other or N/A & $33(13.2)$ \\
\hline \multicolumn{2}{|l|}{ Chinese herbal medicine (kampo) } \\
\hline Use & $78(31.1)$ \\
\hline No use or N/A & $173(68.9)$ \\
\hline
\end{tabular}

Values in parentheses are percentages. Physicians answered with their first choice of treatment for each condition. N/A = No answer; SNRI = serotonin-norepinephrine reuptake inhibitors; $\mathrm{NaSSA}=$ noradrenergic and specific serotonergic antidepressants. 


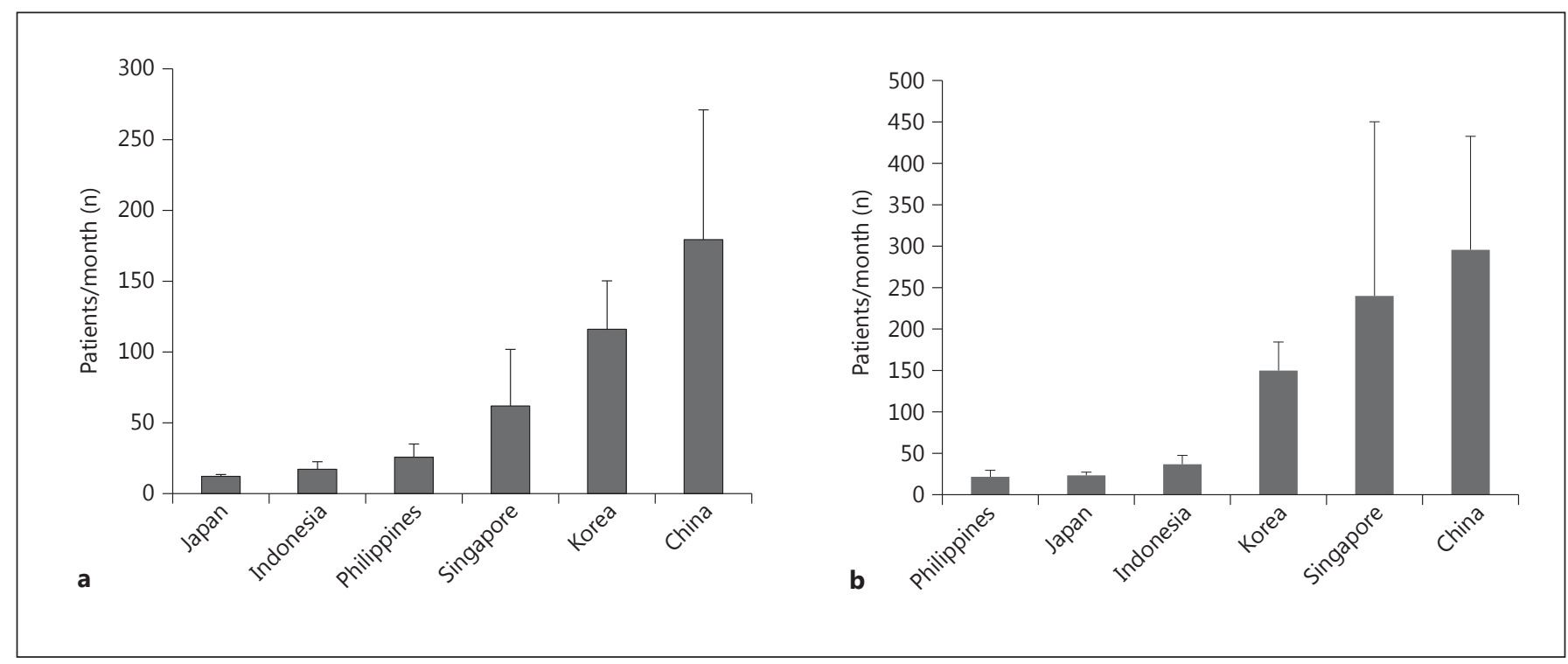

Fig. 1. The number of patients per month per institution with IBS (a) and FD (b), expressed as mean \pm SE. The numbers of physicians responding from each country were as follows: Japan, 131
(IBS) and 130 (FD); Korea, 45; China, 22; Indonesia, 20; the Philippines, 13 , and Singapore, 7 . There were significant differences between the countries: $\mathrm{p}<0.0001(\mathbf{a}, \mathbf{b})$.

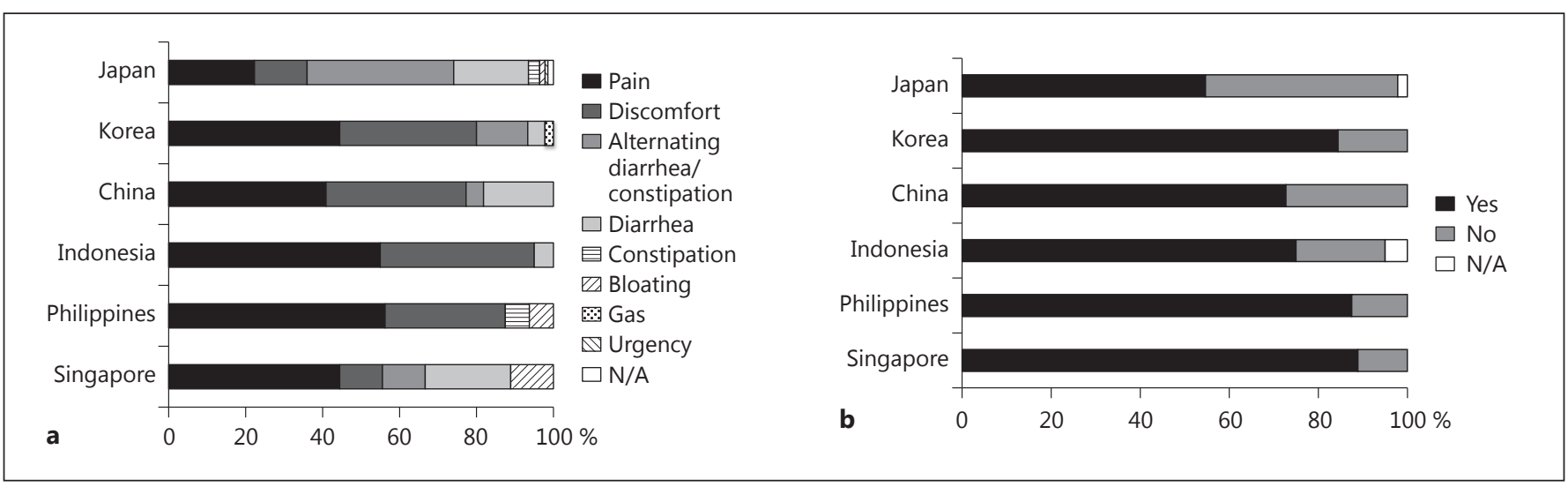

Fig. 2. The most important symptoms in the diagnosis of IBS and the subtyping of IBS. Data are the percentage response to the most important symptoms of IBS (a) and agreement (yes, no or no answer, N/A) of the subtyping of IBS based on the Rome III criteria

\section{Discussion}

This is the first survey comparing clinical practice of IBS among East Asian countries involving a considerable number (251) of physicians. An earlier study on IBS and FD reported on the clinical practice of physicians in the AsiaPacific region [10]. There were similarities in the diagnostic approach, such as differential diagnosis, exclusion of organic diseases, psychophysiological assessment, medical (b) between countries. The numbers of physicians responding from each country were as follows: Japan, 139; Korea, 45; China, 22; Indonesia, 20; the Philippines, 16, and Singapore, 9. There were significant differences between the countries $\mathrm{p}<0.0001$ (a, b).

advice given or medication used, including mild laxatives, antidiarrheal drug, prokinetics and psychological drugs, within the Asia-Pacific region [10]. Furthermore, there was also a difference between Japan and other Asia-Pacific countries as upper gastrointestinal endoscopy and blood examination were more common in Japan, and drugs developed in Japan and Chinese herbal medicines (kampo) were more frequently prescribed in Japan [10]. Therefore, our data are in the same direction with the results of this 


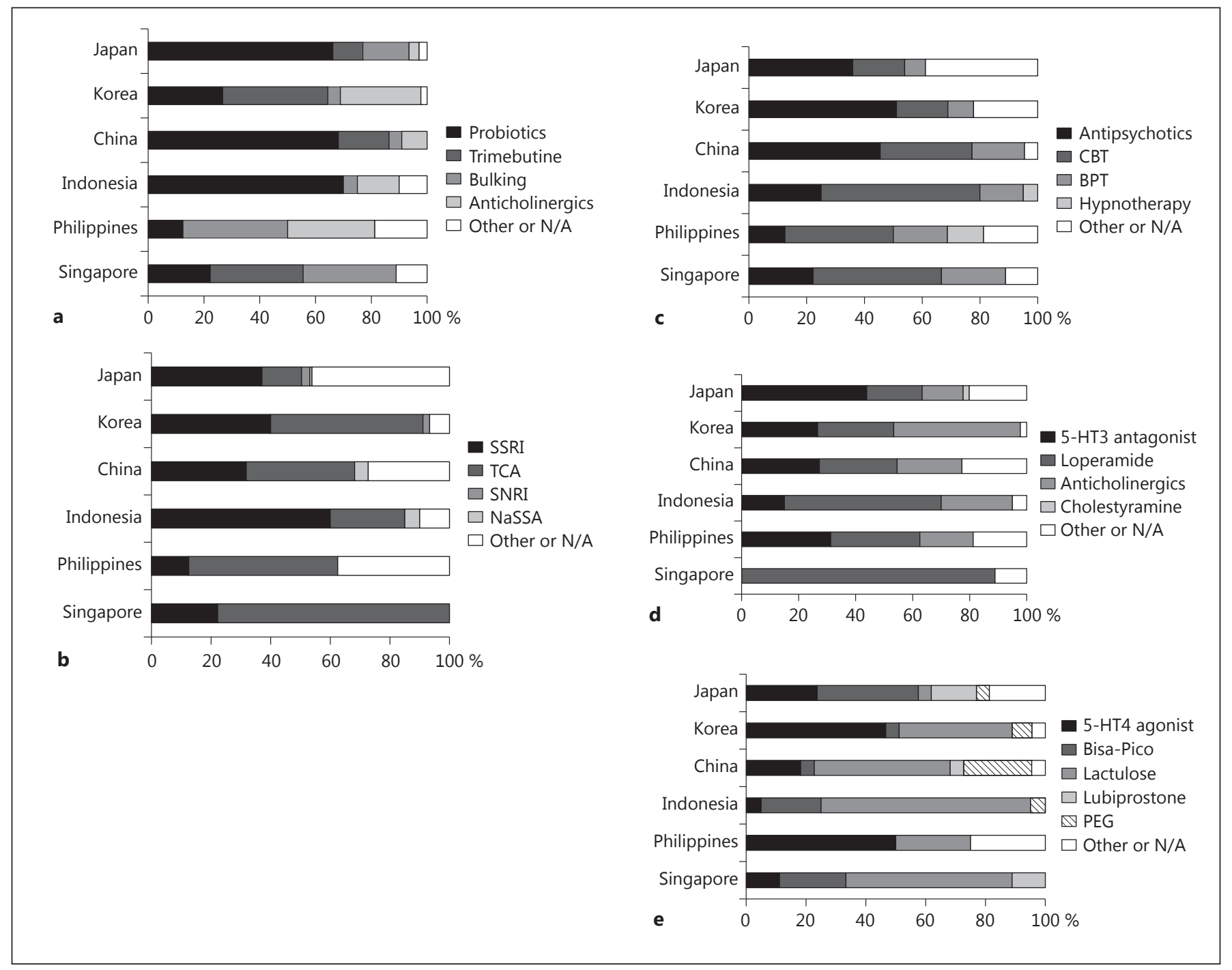

Fig. 3. Treatment comparisons between countries. Data are the percentage use of each treatment in mild (a), moderate (b), severe (c), diarrheal (d) and constipating (e) patients between countries. The numbers of physicians responding from each country were as follows: Japan, 139; Korea, 45; China, 22; Indonesia, 20; the Philippines, 16, and Singapore, 9. There were significant differences between the countries: $p<0.0001(\mathbf{a}-\mathbf{e})$. N/A = No answer; SNRI = serotonin-norepinephrine reuptake inhibitors; NaSSA = noradrenergic and specific serotonergic antidepressants; BPT = brief psychotherapy; PEG = polyethylene glycol.

earlier survey. Our data enabled us to depict a general trend of IBS practice and detailed realities through statistical comparison among East Asian countries.

In this study, the numbers of IBS patients visiting East Asian institutions per month were diverse. Moreover, IBS patients were less frequent than FD patients. This finding is consistent with the earlier report on 818 consecutive outpatients with abdominal symptoms in Japan [11]. Among them, 170 FD and 68 IBS cases were identified [11]. However, the prevalence of FD compared to IBS has not been universally reported. Australian data with a sample size 188 reported that $65 \%$ of patients fulfilled IBS criteria and 62\% accounted for FD [12]. A Mexican database based on the Rome II Modular Questionnaire showed that IBS accounted for $28.9 \%$ of patients whilst FD accounted for only 4.0\% [13]. Even in East Asia, data from 4,638 Chinese college and university students revealed a similar prevalence between FD (9.25\%) and IBS (8.34\%) [14]. There is the possibility of recall bias amongst physicians, easier access to upper gastrointestinal endos- 
copy in East Asia than in Western and Latin countries, or oversight of the impact of overlapping IBS with FD [15] in the institutions in this study. Further investigation of this apparent dominance of FD in comparison to IBS in outpatient clinics in East Asia is warranted.

Differences in clinical practice among the countries were well detected in this survey. The proportion of IBS specialists to nonspecialists also differed markedly, although the survey results suggest that this does not explain the differences in clinical practice. Concerning diagnosis, Japanese physicians favored CBC and CRP and rarely examined stool calprotectin. Although the diagnostic value of stool calprotectin has been recognized [16], it has not been supported by the medical insurance system in some countries, including Japan. Total colonoscopy showed no difference between countries. Colonoscopy has a diagnostic value not only through excluding organic diseases, but also in supporting the existence of a pathophysiology compatible with IBS due to visceral hypersensitivity at colonoscopic procedures and colonic spasm $[17,18]$. There were too few data with which to draw any conclusions regarding the use of capsule endoscopy or CT/MRI colonography in IBS practice. Japanese physicians favored upper gastrointestinal endoscopy and rarely performed flexible sigmoidoscopy, rigid proctoscopy or barium enema. A small number of epidemiological studies of IBS have investigated the utility of diagnostic imaging modalities other than in the colorectal region, including endoscopy in the digestive tract, and reported that upper gastrointestinal endoscopy or ultrasonography, depending on the abdominal symptoms in IBS patients, was beneficial in excluding other conditions in daily clinical practice $[19,20]$. This study suggested that Japanese physicians tried to distinguish IBD from IBS whilst Korean and Chinese physicians placed an emphasis on discriminating microscopic colitis from IBS. This difference may be due to a greater number of patients with microscopic colitis in China or Korea compared to Japan. Histopathological examination of the gut mucosa provides exclusion of collagenous colitis or celiac disease and evidence of increased mucosal permeability with increased mast cells, enterochromaffin cells and inflammatory cells supporting IBS features $[21,22]$. There was no difference in the use of microbial stool test and C. difficile detection between countries. There is insufficient evidence to recommend the routine performance of a standardized battery of diagnostic tests in patients who meet symptom-based criteria for IBS [23]. However, a clinical cohort with a large sample size will solve this problem in the future.
This study revealed differences in the approach to symptoms and diagnosis of IBS among physicians based in East Asian countries. It is natural to assume that abdominal pain and abdominal discomfort are the most important symptoms in IBS based on the Rome III criteria [2]. However, $38.1 \%$ of physicians in Japan considered alternating diarrhea and constipation to be the most important symptoms in IBS. This finding is not specific to Japan. A recent epidemiological survey from the USA clearly indicated that $74 \%$ of medically diagnosed IBS patients and $63 \%$ of undiagnosed IBS subjects reported alternating diarrhea and constipation [24]. Participants in this study supported the Rome III criteria, and even the upcoming Rome IV criteria, regardless of their country of treatment. This notion probably reflects the validity and reliability of the Rome III criteria [25] and positive expectancy of the Rome IV criteria. By contrast, subtyping IBS using the Rome III criteria differed between Japan (54.7\% support) and other countries (72.7-88.9\% support). A clinical survey of 633 outpatients clarified that $31 \%$ satisfied the Rome II criteria for IBS [26]. Among them, 49\% were classified into the alternating diarrhea and constipation type of IBS. Although the term 'alternating diarrhea and constipation' was erased from the Rome III criteria for IBS due to the instability and dependency of data collection frequency, the impact of this symptom on whole IBS pathophysiology should be further explored.

Treatments for mild, moderate, severe, intractable, diarrheal and constipating patients with IBS differed between countries. This is probably due to differences in the availability of pharmacotherapy and nonpharmacological therapy. Evidence exists for the use of probiotics [27], trimebutine [28], bulking polymer [29,30], anticholinergics [30], antidepressants [30], CBT [31], 5-HT3 antagonist [32], 5-HT4 agonist [33] and lubiprostone [34, 35] to relieve the symptoms and pathophysiological features of IBS. Use of antipsychotic drugs is one of the strategies used for severe or intractable patients with IBS [36], but the relatively high rate of use of antipsychotics in Japan, Korea and China was unexpected. These results may be based on some misunderstanding between true antipsychotic drugs and the other psychopharmacological agents used by the respondents. A randomized controlled trial and further evidence are necessary to confirm the use of antipsychotics for IBS in East Asia. Moreover, for intractable IBS patients, treatments for IBD or opioids were used in some countries in this study. There is no evidence of the use of treatments such as mesalazine for IBD in IBS patients [37]. The chronic use of opioids by IBS patients may result in a more complex condition, such as narcotic 
bowel syndrome [38]. The rationale for the treatment realities in IBS practice should be globally checked.

There are some limitations in this study. First, surveyed physicians were selected by the representative IGICS committee members and were not randomly selected from each country. The respondents belonged to a university or large general hospital in urban areas within each country. Information on whether or not our sample was representative of all physicians is necessary in the future. Second, a greater number of physicians were included from Japan and an equal distribution among the East Asian countries was not realized. Therefore, the findings were greatly influenced by data from Japan. Third, we cannot exclude potential participant recall bias. A survey conducted of IBS patients will solve this problem. Further studies on the clinical features of IBS based on recommendations and considerations of the Rome Foundation $[7,39]$ are warranted in the near future.

In conclusion, this survey provided data comparing the clinical practice of IBS among East Asian countries involving a considerable number of physicians. The re- sults supported the first hypothesis that the diagnosis and treatment of IBS differs between countries, but did not generally support the second hypothesis that diagnosis and treatment of IBS differs between IBS specialists and nonspecialists, except for the number of patients treated and some diagnostic testing.

\section{Acknowledgments}

The authors thank all the investigators and physicians who participated in this study. This article was supported by a Grant-inAid from the International Gastrointestinal Consensus Symposium Study Group.

\section{Disclosure Statement}

All authors declare potential conflicts of interest relating to their approval by the management committees of the following organizations: Astellas, Eisai, Abbott Japan, Dainippon-Sumitomo, Ono Pharmaceutical, and Kao.

\section{Appendix}

Questionnaire: Diagnosis and Treatment of IBS in Asia

Please read carefully the following questions. Please provide answers in the blank spaces. Choose one answer to the multiple choice questions.

1. Epidemiology

a Please choose one of followings. You are:

$\square$ General practitioner $\square$ General internist $\quad \square$ Gastroenterologist

\begin{tabular}{l}
$\mathrm{b} \quad$ Are you a specialist in irritable bowel syndrome (IBS)? \\
\hline $\mathrm{c} \quad$ How many patients with IBS per month do you have in your institution? ( \\
\hline $\mathrm{d} \quad$ How many patients with functional dyspepsia (FD) per month do you have in your institution? ( \\
\hline e $\quad$ How many patients with microscopic colitis per year do you have in your institution? ( \\
\hline 2. Diagnosis \\
$\begin{array}{ll}\text { a. What is the most important examination to diagnose IBS? } \\
\square \text { Rome III criteria } \quad \square \text { Microbial stool test }\end{array}$ \\
$\begin{array}{l}\square \text { Colonoscopy } \quad \square \text { Blood chemical examination } \\
\square \text { Histopathology } \quad \square \text { Other (describe: }\end{array}$ \\
$\square$ Barium enema
\end{tabular}

b. What laboratory data do you usually examine at IBS diagnosis?

CBC ( $\square$ Always, $\square$ Often, $\square$ Sometimes, $\square$ Rarely, $\square$ None, $\square$ Not available)

ESR ( $\square$ Always, $\quad \square$ Often, $\quad \square$ Sometimes, $\quad \square$ Rarely, $\quad \square$ None, $\quad \square$ Not available)

CRP ( $\square$ Always, $\square$ Often, $\square$ Sometimes, $\square$ Rarely, $\square$ None, $\square$ Not available)

Stool calprotectin ( $\square$ Always, $\square$ Often, $\square$ Sometimes, $\square$ Rarely, $\quad \square$ None, $\square$ Not available)

Others (describe:

c. What type of endoscopy do you usually use in the diagnosis and evaluation of pathophysiology in IBS?

Rigid proctoscopy ( $\square$ Always, $\square$ Often, $\square$ Sometimes, $\square$ Rarely, $\square$ None)

Flexible sigmoidoscopy ( $\square$ Always, $\quad \square$ Often, $\quad \square$ Sometimes, $\quad \square$ Rarely, $\square$ None)

Total colonoscopy ( $\square$ Always, $\square$ Often, $\square$ Sometimes, $\square$ Rarely, $\square$ None) 
d. Have you used video capsule endoscopy for the diagnosis of IBS? ( $\square$ Y/ $\square$ N/ $\square$ Not available)

e. Do you think that upper GI endoscopy is important for the diagnosis of IBS? ( $\square$ Y/ $\square$ N/ $\square$ I do not know)

f. Do you usually use barium enema in the diagnosis and evaluation of pathophysiology in IBS? $\quad(\square \mathrm{Y} / \square \mathrm{N})$

g. Do you usually use CT/MR colonography in the diagnosis and evaluation of pathophysiology in IBS? $\quad(\square \mathrm{Y} / \square \mathrm{N})$

h. Do you usually use ultrasonography in the diagnosis and evaluation of pathophysiology in IBS? $\quad(\square \mathrm{Y} / \square \mathrm{N})$

i. What is the major role of histopathology in the diagnosis and evaluation of pathophysiology in IBS?

$\square$ Distinguishing IBS from IBDs

$\square$ Distinguishing IBS from microscopic colitis

$\square$ Detection of low grade inflammation in IBS

$\square$ Other (describe:

j. What are the major diseases in differential diagnosis of IBS in your country? (describe: )

3. Microbial investigations

a. Do you usually perform microbial stool test at each flare of disease in patients with an established diagnosis of IBS?

$(\square \mathrm{Y} / \square \mathrm{N})$

b. Do you usually perform stool test for Clostridium difficile in severe or refractory patients with IBS?

$(\square \mathrm{Y} / \square \mathrm{N})$

4. Classification

a. Do you use subtypes of IBS (IBS-D, IBS-C, IBS-M, and IBS-U) based on Rome III criteria in daily routine clinical practice?

$(\square \mathrm{Y} / \square \mathrm{N})$

b. What kind of symptom do you think is the most important in patients with IBS in your country?

$\square$ Abdominal pain

$\square$ Abdominal discomfort

$\square$ Diarrhea

$\square$ Constipation

$\square$ Alternating diarrhea and constipation

$\square$ Abdominal bloating

$\square$ Gas

$\square$ Urgency

$\square$ Difficulty in defecation

$\square$ Incomplete evacuation

$\square$ Mucus

$\square$ Other (describe:

5. Management

a. What is your first choice for the treatment of newly diagnosed IBS regardless of subtypes?

1) Mild IBS

$\square$ Probiotics $\quad \square$ Bulking polymer $\quad \square$ Anticholinergics $\quad \square$ Trimebutine $\quad \square$ Others (describe:

2) Moderate IBS

$\square$ Tricyclic antidepressants $\quad \square$ SSRI $\quad \square$ SNRI $\quad \square$ NaSSA $\quad \square$ Others (describe:

3) Severe IBS

$\square$ Cognitive behavior therapy $\quad \square$ Hypnotherapy $\quad \square$ Brief psychotherapy $\quad \square$ Antipsychotic medication

$\square$ Others (describe:

b. What is your first choice for the treatment of newly diagnosed IBS along subtypes?

1) IBS-D

$\square$ 5-HT3 antagonist $\square$ Loperamide $\quad \square$ Cholestyramine $\square$ Anticholinergics $\quad \square$ Others (describe:

2) IBS-C

$\square$ 5-HT4 agonist

$\square$ Lubiprostone

$\square$ PEG $\square$ Lactulose

$\square$ Bisacodyl/picosulfate

$\square$ Others (describe: )

c. Do you usually prescribe the following agents to intractable IBS patients?
$\square$ Steroid
$\square$ 5-ASA
$\square$ Opioid
$\square$ NSAIDs
$\square$ Pregabalin
$\square$ Others (describe:

d. Do you use (Chinese) herbal medicine in daily routine clinical practice for IBS?

$(\square \mathrm{Y} / \square \mathrm{N})$

e. Are you interested in managing patients with IBS?

$(\square \mathrm{Y} / \square \mathrm{N})$

f. Do you agree to use Rome III criteria in your country?

$(\square \mathrm{Y} / \square \mathrm{N})$

g. Are you going to use Rome IV criteria which will be published in Gastroenterology in 2016?

$(\square \mathrm{Y} / \square \mathrm{N})$ 


\section{References}

1 Drossman DA: The functional gastrointestinal disorders and the Rome III process. Gastroenterology 2006;130:1377-1390.

- 2 Longstreth GF, Thompson WG, Chey WD, Houghton LA, Mearin F, Spiller RC: Functional bowel disorders. Gastroenterology 2006;130:1480-1491.

-3 Lovell RM, Ford AC: Global prevalence of and risk factors for irritable bowel syndrome: a meta-analysis. Clin Gastroenterol Hepatol 2012;10:712-721.

-4 Gralnek IM, Hays RD, Kilbourne A, Naliboff B, Mayer EA: The impact of irritable bowel syndrome on health-related quality of life. Gastroenterology 2000;119:654-660.

5 Canavan C, West J, Card T: Review article: the economic impact of the irritable bowel syndrome. Aliment Pharmacol Ther 2014;40: 1023-1034.

6 Chang L, Toner BB, Fukudo S, Guthrie E, Locke GR, Norton NJ, Sperber AD: Gender, age, society, culture, and the patient's perspective in the functional gastrointestinal disorders. Gastroenterology 2006;130:1435-1446.

-7 Sperber AD, Gwee KA, Hungin AP, Corazziari E, Fukudo S, Gerson C, Ghoshal UC, Kang JY, Levy RL, Schmulson M, Dumitrascu D, Gerson MJ, Chen M, Myung SJ, Quigley EM, Whorwell PJ, Zarzar K, Whitehead WE: Conducting multinational, cross-cultural research in the functional gastrointestinal disorders: issues and recommendations: a Rome Foundation working team report. Aliment Pharmacol Ther 2014;40:1094-1102.

8 Hehemann JH, Correc G, Barbeyron T, Helbert W, Czjzek M, Michel G: Transfer of carbohydrate-active enzymes from marine bacteria to Japanese gut microbiota. Nature 2010;464:908-912.

-9 Gwee KA, Bak YT, Ghoshal UC, Gonlachanvit S, Lee OY, Fock KM, Chua AS, Lu CL, Goh KL, Kositchaiwat C, Makharia G, Park HJ, Chang FY, Fukudo S, Choi MG, Bhatia S, Ke M, Hou X, Hongo M, Asian Neurogastroenterology and Motility Association: Asian consensus on irritable bowel syndrome. J Gastroenterol Hepatol 2010;25:1189-1205.

10 Miura S, Sugano K, Kinoshita Y, Fock KM, Goh KL, Gibson P, et al: Diagnosis and treatment of functional gastrointestinal disorders in the Asia-Pacific region: a survey of current practices. J Gastroenterol Hepatol 2011; 26(suppl 3):2-11.

11 Okumura T, Tanno S, Ohhira M, Tanno S: Prevalence of functional dyspepsia in an outpatient clinic with primary care physicians in Japan. J Gastroenterol 2010;45:187-194.

12 Bennett EJ, Piesse C, Palmer K, Badcock CA, 25 Tennant CC, Kellow JE: Functional gastrointestinal disorders: psychological, social, and somatic features. Gut 1998;42:414-420.

-13 Schmulson M, Adeyemo M, Gutiérrez-Reyes G, Charúa-Guindic L, Farfán-Labonne B, Ostrosky-Solis F, Díaz-Anzaldúa A, Medina L, Chang L: Differences in gastrointestinal symptoms according to gender in Rome II positive IBS and dyspepsia in a Latin Ameri- can population. Am J Gastroenterol 2010;105: 925-932.

14 Dong YY, Chen FX, Yu YB, Du C, Qi QQ, Liu H, Li YQ: A school-based study with Rome III criteria on the prevalence of functional gastrointestinal disorders in Chinese college and university students. PLoS One 2013; 8:e54183.

15 Talley NJ, Dennis EH, Schettler-Duncan VA, Lacy BE, Olden KW, Crowell MD: Overlapping upper and lower gastrointestinal symptoms in irritable bowel syndrome patients with constipation or diarrhea. Am J Gastroenterol 2003;98:2454-2459.

16 Dolwani S, Metzner M, Wassell JJ, Yong A, Hawthorne AB: Diagnostic accuracy of faecal calprotectin estimation in prediction of abnormal small bowel radiology. Aliment Pharmacol Ther 2004;20:615-621.

17 Kim ES, Cheon JH, Park JJ, Moon CM, Hong SP, Kim TI, Kim WH: Colonoscopy as an adjunctive method for the diagnosis of irritable bowel syndrome: focus on pain perception. J Gastroenterol Hepatol 2010;25:1232-1238.

18 Jung HK, Choung RS, Locke GR 3rd, et al: Diarrhea-predominant irritable bowel syndrome is associated with diverticular disease: a population-based study. Am J Gastroenterol 2010;105:652-661.

19 Güçlü M, Pourbagher A, Serin E, et al: Ultrasonographic evaluation of gallbladder functions in patients with irritable bowel syndrome. J Gastroenterol Hepatol 2006;21: 1309-1312.

20 Spiegel BM, DeRosa VP, Gralnek IM, et al: Testing for celiac sprue in irritable bowel syndrome with predominant diarrhea: a cost-effectiveness analysis. Gastroenterology 2004; 126:1721-1732.

21 Ford AC, Chey WD, Talley NJ, et al: Yield of diagnostic tests for celiac disease in individuals with symptoms suggestive of irritable bowel syndrome: systematic review and metaanalysis. Arch Intern Med 2009;169:651-658.

22 Limsui D, Pardi DS, Camilleri M, et al: Symptomatic overlap between irritable bowel syndrome and microscopic colitis. Inflamm Bowel Dis 2007;13:175-181.

23 Cash BD, Schoenfeld P, Chey WD: The utility of diagnostic tests in irritable bowel syndrome patients: a systematic review. Am J Gastroenterol 2002;97:S7-S26

24 Hungin AP, Chang L, Locke GR, Dennis EH, Barghout V: Irritable bowel syndrome in the United States: prevalence, symptom patterns and impact. Aliment Pharmacol Ther 2005; 21:1365-1375.

5 Jellema P, van der Windt DA, Schellevis FG, et al: Systematic review: accuracy of symptom-based criteria for diagnosis of irritable bowel syndrome in primary care. Aliment Pharmacol Ther 2009;30:695-706.

26 Shinozaki M, Fukudo S, Hongo M, Shimosegawa T, Sasaki D, Matsueda K, Harasawa S, Miura S, Mine T, Kaneko H, Arakawa T, Haruma K, Torii A, Azuma T, Miwa H, Fukunaga M, Handa M, Kitamori S, Miwa T, et al:
High prevalence of irritable bowel syndrome in medical outpatients in Japan. J Clin Gastroenterol 2008;42:1010-1016.

27 Moayyedi P, Ford AC, Talley NJ, et al: The efficacy of probiotics in the treatment of irritable bowel syndrome: a systematic review. Gut 2010;59:325-332.

28 Tack J: Systematic review: the efficacy of treatments for irritable bowel syndrome: a European perspective. Aliment Pharmacol Ther 2006;24:183-205.

29 Bijkerk CJ, Muris JW, Knottnerus JA, et al: Systematic review: the role of different types of fibre in the treatment of irritable bowel syndrome. Aliment Pharmacol Ther 2004;19:245-251.

30 Ruepert L, Quartero AO, de Wit NJ, van der Heijden GJ, Rubin G, Muris JW: Bulking agents, antispasmodics and antidepressants for the treatment of irritable bowel syndrome. CochraneDatabaseSystRev2011;8:CD003460.

- 31 Zijdenbos IL, de Wit NJ, van der Heijden GJ, et al: Psychological treatments for the management of irritable bowel syndrome. Cochrane Database Syst Rev 2009;1:CD006442.

32 Fukudo S, Ida M, Akiho H, Nakashima Y, Matsueda K: Effect of ramosetron on stool consistency in male patients with irritable bowel syndrome with diarrhea. Clin Gastroenterol Hepatol 2014;12:953-959.e4.

33 Kanazawa M, Watanabe S, Tana C, Komuro H, Aoki M, Fukudo S: Effect of 5-HT4 receptor agonist mosapride citrate on rectosigmoid sensorimotor function in patients with irritable bowel syndrome. Neurogastroenterol Motil 2011;23:754-e332.

34 Fukudo S, Hongo M, Kaneko H, Ueno R: Efficacy and safety of oral lubiprostone in constipated patients with or without irritable bowel syndrome: a randomized, placebo-controlled and dose-finding study. Neurogastroenterol Motil 2011;23:544-e205.

35 Fukudo S, Hongo M, Kaneko H, Takano M, Ueno R: Lubiprostone increases spontaneous bowel movement frequency and quality of life in patients with chronic idiopathic constipation. Clin Gastroenterol Hepatol 2014, Epub ahead of print.

-36 Drossman DA: Beyond tricyclics: new ideas for treating patients with painful and refractory functional gastrointestinal symptoms. Am J Gastroenterol 2009;104:2897-2902

37 Hanevik K, Dizdar V, Langeland N, et al: Tolerability and effect of mesalazine in postinfectious irritable bowel syndrome. Aliment Pharmacol Ther 2011;34:259-260.

38 Drossman D, Szigethy E: The narcotic bowel syndrome: a recent update. Am J Gastroenterol 2014;2:22-30.

39 Schmulson M, Corazziari E, Ghoshal UC, Myung SJ, Gerson CD, Quigley EM, Gwee KA, Sperber AD: A four-country comparison of healthcare systems, implementation of diagnostic criteria, and treatment availability for functional gastrointestinal disorders: a report of the Rome Foundation Working Team on cross-cultural, multinational research. Neurogastroenterol Motil 2014;26:1368-1385. 